\title{
A Química é divertida
}

\section{Doze anos de promoção da Química na Madeira}

HELENA TOM Ás *

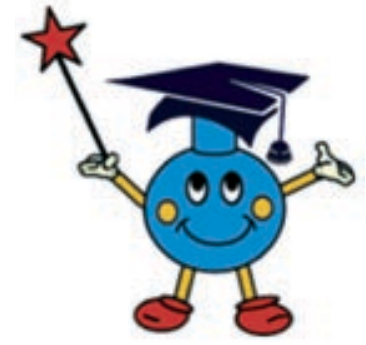

Ainda não se falava no decréscimo de vocações em Química e já a promoção e divulgação da Química e da Bioquímica faziam parte do leque de actividades do Departamento de Química da Universidade da Madeira (UMa). A primeira edição da acção A QUÍMICA É DIVERTIDA ocorreu em 1995, tendo vindo depois a realizar-se quase todos os anos, mantendo, em geral, a mesma designação e o mesmo leque de actividades (demonstrações experimentais, colóquios, "portas abertas", etc.). Em 1996 e 1997, a Rua do Castanheiro, em pleno centro do Funchal e onde, à data, se localizavam os laboratórios de Química (actualmente apenas a Reitoria aí se encontra), chegou mesmo a ser iluminada com motivos alusivos ao evento durante o período natalício. Já em 2000 e 2001, A QUÍMICA É DIVERTIDA decorreu durante a feira INFOFUTUR realizada no Madeira Tecnopólo.

Nos últimos anos, A QUÍMICA É DIVERTIDA tem sido efectuada no âmbito da Semana da Ciência e da Tecnologia, em Novembro, numa organização conjunta do Departamento de Química da Universidade da Madeira e do Centro de Química da Madeira (CQM), unidade de investigação criada em 2004 e apoiada pela Fun-

* Departamento de Química da Universidade da Madeira e investigadora do Centro de Química da Madeira dação para a Ciência e a Tecnologia. Assim, para além das actividades habituais, todos os participantes têm tido oportunidade de conhecer os trabalhos de investigação levados a cabo no seio do CQM, nas áreas dos produtos naturais e dos materiais. $\mathrm{Na}$ última edição, em Novembro último, a acção contou com o apoio da Agência Nacional para a Cultura Científica e Tecnológica Ciência Viva, o qual se estenderá até 2008. As sessões experimentais contemplaram diferentes faixas etárias do público-alvo em

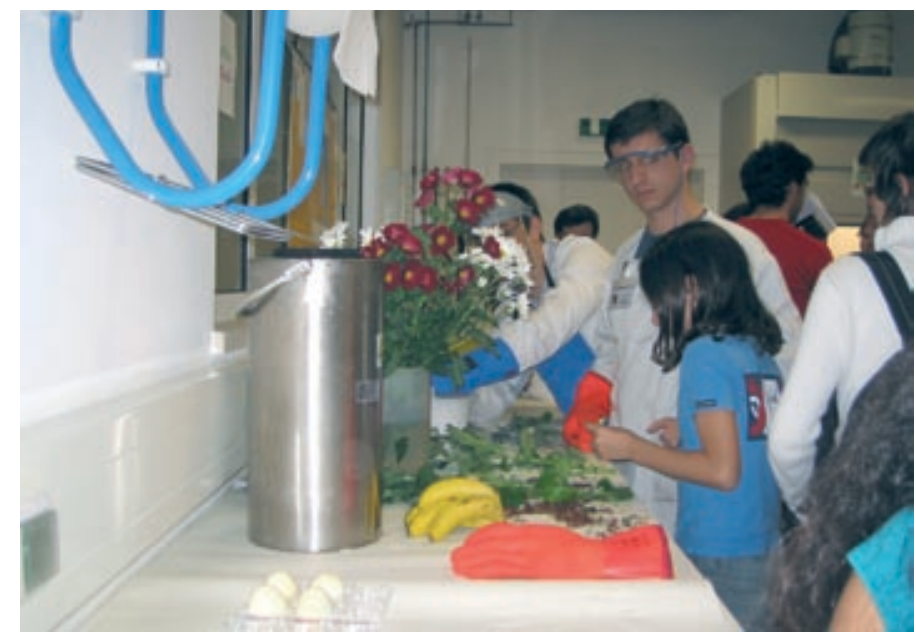

Experiências com azoto líquido

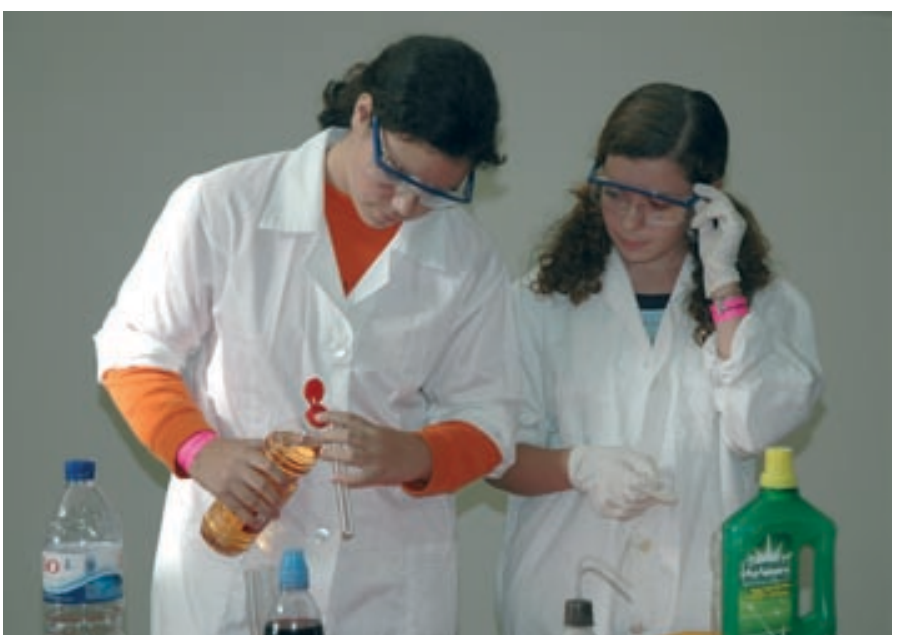

Concurso A EXPERIÊNCIA MAIS DIVERTIDA (2006) 
Visita de crianças do jardim de infância

dias separados (um dia destinado a crianças do jardim de infância, outro a alunos do $1 .^{\circ}$ e $2 .^{\circ}$ ciclos do ensino básico e outro a alunos do $3 .^{\circ}$ ciclo do ensino básico e do ensino secundário), num total de cerca de 500 visitantes, metade dos quais da zona norte da ilha. No concurso A EXPERIÊNCIA MAIS DIVERTIDA participaram 12 equipas (cada uma com um professor e dois estudantes) que apresentaram um total de 18 experiências.

Iluminações de Natal na Rua do Castanheiro, Funchal (1996)

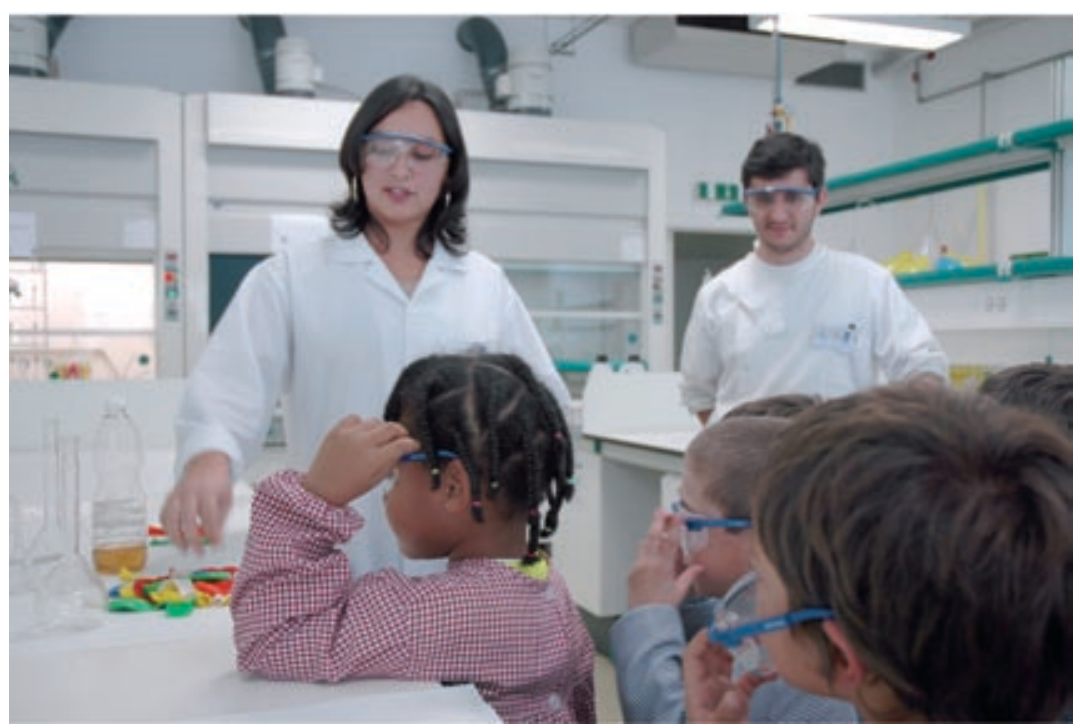

A QUÍMICA É DIVERTIDA teve sempre muita receptividade por parte das crianças e jovens madeirenses e muito contribuiu para a disseminação de acções da mesma natureza em escolas da Região Autónoma da Madeira. Além desta iniciativa, o Departamento de Química da UMa e o Centro de Química da Madeira têm estado envolvidos noutras actividades de promoção e divulgação da ciência, desde a Ocupação Cientí- fica de Jovens nas Férias, até à organização de colóquios nas escolas da Madeira, passando pelo apoio a iniciativas de promoção da Química por parte das escolas e dos órgãos de comunicação social.

(mais informações em: http://www. uma.pt/quimicadivertida)

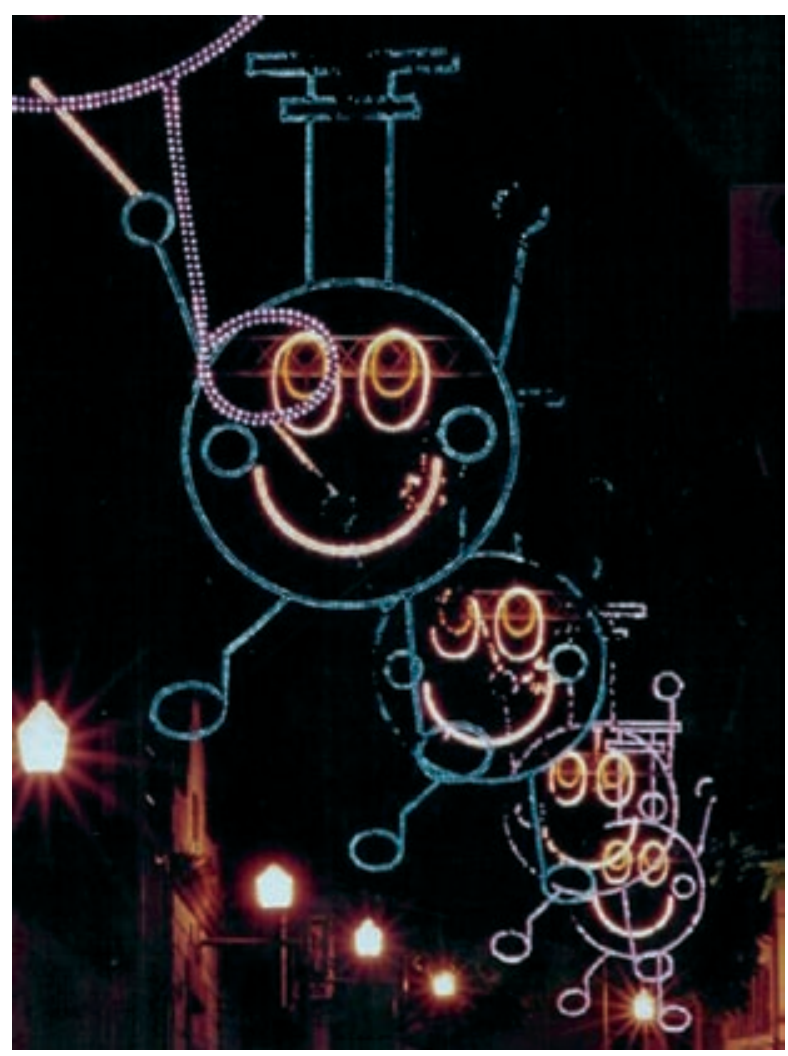

